\title{
English to Persian Translation Accuracy of "Rulles and Regulations" of In-Ternational Banking System
}

\author{
Saeed Fathi-Alishah ${ }^{1}$, Samad Sajjadi ${ }^{2}$, Mohammad Reza Kooroghli ${ }^{1}$, and Ali \\ Salahi-Yekta² \\ ${ }^{1} E$ nglish Language Department, Islamic Azad University, Parand Branch, Tehran, Iran \\ ${ }^{2}$ School of Allied Medical Sciences, Shahid Beheshti University of Medicxal Sciences, Tehran, Iran
}

\section{Abstract}

This study comparatively analyzed the English to Persian translations of "rules and regulations" of the international banking system, at lexicon, phrase, sentence and paragraph levels to find out if the translations had been semantically comparable to their English versions. The translated texts, together with their English scource texts, were handed in to raters to assess and score semantically based on a three-point scale of "incorrect", "fair" and "correct". According to the results, the majority (96\%) of

Corresponding Author:

Samad Sajjadi

samad_sajadi@sbmu.ac.ir

Received: 1 July 2019

Accepted: 18 July 2019

Published: 31 July 2019

Publishing services provided by Knowledge

(c) Saeed Fathi-Alishah et al. This article is distributed under the terms of the Creative Commons Attribution License, which permits unrestricted use and redistribution provided that the original author and source are credited.

Selection and Peer-review under the responsibility of the AICLL 2019 Conference Committee. lexicons had been translated correctly into Persian, while a small percentage of translated lexicons $(3 \%)$ had a fair quality and an even smaller percentage (1\%) were incorrectly translated. As for the phrases, most of them (86\%) had been translated correctly into Persian, while a small percentage of translated phrases (8\%) had a fair quality and an even smaller percentage (6\%) had been incorrectly translated. Regarding sentences, $44 \%$ of their translations had a good and $44 \%$ had fair quality, whereas some smaller numbers $(12 \%)$ had been incorrectly translated. Compared to previous components, i.e. lexicon and phrases, the percentage of incorrect translations had noticeably increased at the level of sentence. Yet, the mean words in Persian sentences (i.e., 23.48) were rather similar to the source language sentences (i.e., 25.72). Regarding paragraphs, the majority (40\%) of the translations had either a good or fair quality, while a significant number $(20 \%)$ had been incorrectly translated. So, unlike the lexicons and phrases, a significant number of sentences and paragraphs had semantically been inaccurately translated. In addition, the mean number of words in Persian paragraphs (64.6) was considerably smaller than the mean words in English paragraphs (71.1).

Keywords: Semantic accuracy in translation, English to Persian, Banking rules and regulations

\section{Introduction}

Translation has played a significant role in establishing communication links between human beings since long time ago, but recently, with rapid advances in different areas of technology, including digital translation tools, translation has undergone fundamental 
changes (Doherty, 2016). Along with the development of translation tools, translation studies have also increased significantly, and are expected to grow even further in the $21^{\text {st }}$ century (Lefevere, 2004).

Translation of field specific, technical texts, like those of the the banking system, is of special impportance. Translation in such sectors requires specialists who are familiar with both the source and target legal systems. That is why an advanced level of expertise is required in field-specific translations. As such, a person who does not have the necessary expertise of the materials under translation may ignore the main concept when translating technical terms (Goyal, 2013; Alwazna, 2013; Lefevere, 2004).

With these points in mind, the researchers in this study are intended to find out if the banking rules and conventions have been accurately translated from English into Persian at different levels, from vocabulary items to paragraphs and longer texts. So, bearing in mind the significance of translation in banking system, the current study is intended to investigate the translation quality of "rules and regulations" of the international banking from English into Persian.

\section{Literature Review}

Field-specific translation, including that of the banking system texts, has its own status in various respects (Cao, 2007). The translator should be completely aware of the exact purpose and meaning of the source text as it is a kind of translation of the language used for a specific purpose (Alwazna, 2013). There are people who use online translation machines (e.g. Google Translate) to get a general grasp of the foreign text taken from an email, Web pages, or other computer-based sources. However, on-line translation machines still lag behind in producing an accurate equivalent, similar to what could be done by a human professional translator, while inaccuracy in translating sensitive texts, like the banking system, can have grave consequences (Aiken \&Balan, 2011).

The translator must have expert knowledge in the particular field he or she is translating; that is, the translator should be armed with subject knowledge, writing skills, research skills, text type familiarity, and sufficient translation skills to reder a proper translation of the source text (Byrne, 2006). So, the translator's subject knowledge and his/her translation ability are extremely important in achieving good translation (Byrne, 2006). Then, the translators should do their best to make the target text semantically look like as closely as possible to the source text (House, 1997; Harvey, 2002).

As such, precision is of special significance in translating legal texts in the banking system. In all texts, including legal and official texts, pragmatics and the main sense 
of the text is of paramount importance. Evaluation of translation precision would then require the study of the source and target texts in detail with due attention to semantic and pragmatic issues under focus (Robinson, et al, 2006). To make sure if a legal text in the banking system follows a sematically accurate translation, the professionals need to find out if the translated texts are lexically and semantically comparable to their original texts. (Zhao, 2000; Sarcevic, 1997).

Hence, for success in translation, the translator has to be familiar with field-specific terminologies and expressions. Banking can be defined as a professional activity which invloves accepting and keeping other individuals' money, lending out this money in order to earn a profit while a banking system can be defined as a mechanism in which the money of a country is supported and controlled. So proper knowledge of field related words and expressions can help to achieve more accurate translation of sensitive concepts, when translating banking documents from source to the target language (Goyal, 2013).

Banking translation consists of a very sensitive process. Appropriate and conversant translators should be taught how to translate banking texts which are different from other documents in the language they use and the purpose they follow, and the translators should accordingly be prepared to adopt the right diction to transfer the intended aims and objectives from the source into the target text. This way, the translated texts would share the semantically sensitive features of the specialized source texts (Zralka, 2007; Doherty, 2016).

Loyalty to the concepts of the source text is also of special importance in rendering highly sensitive materials like the Baking materials. Lack of conceptual accuracy in such texts can have grave consequences, particularly in that capital loss can happen if the concepts have not been semantically well transferred. Comparative analysis of vsemantic concepts is a suitable way of assessing the accuracy of the translated texts (Nord, 2006). This way, paragraphs, and their components like phrases and sentences will be semantically compared to find out how accurately they have been rendered into the target language. Then the author can find out whether the translators observed the principle of faithfulness, as indicated in Nord's (2006) and Chirila's (2016) assertions in converting source materials into the intended target language.

With these issues in mind, the researchers were curious to find out if Persian translations of "rules and regulations" of the international banking system, were similar in meaning to their English equivalents. The researchers' initial review indicated inaccuracies at phrase and sentence levels, but they intended to find out whether the inaccuracies were statistically significant. So, to make sure of the size and nature of 
the inaccuracies, the researchers decided to formulate a research project in order to semantically investigate the quality of translations. To this end, the researchers randomly selected a sample of the translations at word, phrase, sentence and paragraph levels and compared them against their English versions semantically to know how accurately they had been translated.

\section{Research Method}

In line with the study's objectives, the researchers postulated and tested a number of research questions $(R Q)$, as follows:

RQ1. Is Persian translation of the banking system "rules and regulations" semantically comparable to its source text in English at the level of lexicon?

RQ2. Is Persian translation of the banking system "rules and regulations" semantically comparable to its source text in English at the level of phrase?

RQ3. Is Persian translation of the banking system "rules and regulations" semantically comparable to its source text in English at the level of sentence?

RQ4. Is Persian translation of the banking system "rules and regulations" semantically comparable to its source text in English at the level of paragraph?

\subsection{Selection of the texts}

Given the scope of the study and the sheer size of the booklet on "Rules and Regulations" of the international banking system, the researcher had to choose the necessary materials before taking them to the raters for evaluation and scoring. Random selection was the main criteria for selecting the texts. As such the following procedures were adopted in randomly choosing the intended items.

Lexicons: To answer the first research question, 100 lexicons were randomly selected from the even pages of the "Rules and Regulations" document, with three words per page on average. Then the raters were asked to assess and rate the translation of each lexicon in terms of comprehensibility, accuracy, and appropriateness, on a three-point Likert scale, comprising "Incorrect", "Fair", and "Correct".

Phrases: 50 phrases were randomly selected from the even pages of the document, with two phrases per page on average. Attempts were made not to select phrases whose lexicons had previously been selected. Rating was performed similarly to the 
case of lexicon. Here, the words in English and Farsi phrases were also enumerated and compared.

Sentences: 25 sentences were randomly selected from the odd pages of the document, with one sentence per page on average. Rating was performed similarly to the case of lexicons and phrases. Here, too, the English sentences and their Persian translations were carefully assressed, compared and scored by the raters.

Paragraphs: To answer question number 4 , the intended paragraphs were selected from the entire document while excluding paragraphs with parts (i.e., lexicon, phrase, or sentence) had previously been selected for word, phrase and sentence analyses. This way, a total of 10 paragraphs were randomly selected from the remaining texts and handed in to the raters for further analysis and scoring.

\subsection{The raters}

Two raters, besides the researcher and the supervisor, were involved in the assessment and scoring procedure. The main role of the researchers was the selection, collection and tabulation of the data. The researchers provided the data, and then handed them in to the raters for analysis. The raters were briefed on the main intention of the study and their duties in analyzing and scoring the texts. The raters were expert in their field of study. They were EFL teachers with a post graduate degree in applied linguistics. They were well familiar with text evaluation and rating. They were supposed to rate the translated texts based on the Likerts scale for lexicon and semantic accuracy, in line with the research questions of the study. Familiarity with banking text and native-like English proficiency were two important criteria in choosing the raters.

\subsubsection{The overall procedure}

The English version of "rules and regulations" of the international banking system, serving as the source text, was obtained from the documents available in the "Parsian Bank" in Tehran. The Persian translation of the same text that is commonly used in the Iranian banking systems was also collected from the Parsian Bank. Then the randomly selected texts from both versions of the documents, i.e. the Source in English and the target texts in Persian, were handed in to the raters to read, judge and score. In a session arranged by the researchers, the raters were briefed on the aims of the study, with the necessary instructions on the evaluation and rating procedures, including 
ways of scoring the texts based on a Likert Scale. The raters were well familier with the marking procedure of its implementation in scoring the texts.

Some example sentences on the intended manner of rating and scoring were presented to the raters. After detailed discussion on what the raters were expected to do, their questions were discussed in detail to remove any ambiguities left. All the materials were then handed in to the raters to carry out the rating task. The two raters were asked to compare the source materials and their target translations and then score each section (i.e. words, phrases, sentences and paragraphs) separately based on a three-point scale, with score 1 denoting incorrect, 2 signifying fair and 3 indicating good.

Following the rating procedures, the raters returned the stuff with the scores considered for the translation on different components of the texts back to the researchers. As already been indicated, they rated the words, phrases, sentences and paragraphs separately. Due to time limit, and the scope of the study, they were told to evaluate and rate just a selection of the materials. Of course random procedure in material selection was of special importance and was followed with great care. The scores obtained on different sections of the data were then tabulated and subjected to a number of statistical analyses.

\section{Results and Discussion}

The analyses deal with the statistical analyses, mainly the accuracy rate in percent and mean average, carried out to test research question. The analyses for each component (i.e., words, phrases, sentences and paragraphs) were considered separately, along the lines of research questions as follows.

Research Question 1 aimed at comparing the Farsi translation and the original English text at the level of lexicon. The raters had compared the translation of each lexicon in terms of comprehensibility, accuracy, and appropriateness, on a three-point scale, comprising "Incorrect", "Fair", and "Correct". Based on the results, a majority (96\%) of lexicons had been translated correctly into Persian, while a small percentage of the translated lexicons (3\%) had a fair quality and an even smaller percentage (1\%) had been incorrectly translated. Therefore, the Persian translation of the banking system rules and regulations is semantically comparable to its English counterpart at the level of lexicon.

Research Question 2 aimed at comparing the Farsi translation and the original English text at the level of phrase. In line with this question, the raters checked the semantic 
accuracy of the phrases using a three-point scale of "Incorrect", "Fair", and "Correct". The majority (86\%) of the phrases had been translated correctly into Farsi, while a small percentage of translated phrases (8\%) had a fair quality and an ever smaller percentage (6\%) were incorrectly translated. Furthermore, the mean number of words in English (3.28) and Persian (2.92) phrases was rather similar.

Research Question 3 aimed at comparing the Persian translations of sentences with their original English sentences. Rating was performed similarly to the case of lexicons and phrases. According to the results, the majority (44\%) of translated sentences had either a good or fair quality, whereas a smaller number of the sentences (12\%) had been incorrectly translated. Compared to previous cases, i.e. lexicon and phrases, the percentage of correctly translated cases has decreased a lot at the level of sentence. Yet, the mean number of words in English (25.72) and Persian (23.48) sentences was relatively similar.

Research Question 4 aimed at comparing the Persian translations and the original English texts at the level of paragraph. Rating was performed similarly to the previous cases, and the number of words in English and Farsi paragraphs was counted and compared. The majority (40\%) of translated paragraphs had either a good or fair quality, while a smaller proportion of the paragraphs (20\%) had been incorrectly translated. Similar to the case of sentences and contrary to the case of lexicons and phrases, the percentage of correctly translated cases is low. In addition, the number of words in Persian (64.6) paragraphs is considerably smaller than that in English (71.1) paragraphs.

Based on the results, at the level of lexicon and phrase, the Farsi translation of the mentioned texts is semantically comparable to the original English version, and the number of words (at the level of phrase) is also comparable across the two languages. At other levels, however, the Persian translation distanced itself from its English counterpart, and the number of words in the two languages also differed considerably. Therefore, when considered at the larger scale of sentences and paragraphs, the problem issues in the Persian translation become apparent, while such problems were not present at the level of lexicon and phrase.

The precision problem in Persian translation of the docuemts contradicts the translator's commitment to equivalence in source to target translation of the text. This way, the translator fails to remain loyal to the original text as closely as possible, that is the banking documents with highly sensitive connotations. So, bearing in mind the significance of accuracy in such translations, greater precision is required of translators (cf. Gawron-Zaborska 2000, Kasirer 2000: 57). In the current study, the translator had semantically achieved suitable accuracy at word and phrase levels, with 96\% and 94\% 
accuracy rates. However, translations at sentence and paragraph levels, with $88 \%$ and $80 \%$ accuracy rates, fell short of the expected precision level for important documents like the internationally used banking "rules and regulations". This contradicts the UN Instructions for translators, maintaining that "fidelity to the original text must be the first consideration" (quoted by Sarcevic 1997: 16).

Similarly, precision in translation goes beyond semantic accuracy to include the length of text as well. Translators are advised not to alter the length of sentences to avoid imposing their own interpretation (Beyer \& Conradsen 1995: 164). Such literal view of fidelity shows the positivist tradition in legal interpretation, which maintains that the meaning of a legislative text is "declared," but not created, by the translator (Kasirer 2000:57-59). A similarly narrow view of loyalty is indicated by court interpreters (Morris 1995: 266). Since lawyers are well aware of the empowering nature of language, they do not want to grant the translators the free choice of words. In the current study, the translator had partially ignored the fidelity principle by reducing the size of the translated texts at phrase, sentence and paragraph levels.

So if the translators of the bank documents want to achieve source-to-target translation equivalence, they should pay due attention to both the meaning and the length of the texts under translation. Precision in meaning could avoid conceptual misunderstanding and loyalty to text size could produce the same concepts as intended by the writer of the source texts. Added to these is the skill of the translator in producing high quality translation. Given the significance of bank documents and grave consequences caused by their inaccurate translation, they should be translated by professional trtanslators, with sufficient experience in rendering texts from the source into the target language. This way, the texts that are re-contextualized into the target language could be relied on with no worries about precision in their meaning and length.

\section{Conclusion}

This study dealt with accuracy of translations of banking rules and regulations that are of common use in Iran and other countries worldwide. Based on the results, the researchers concluded that the Persian translations of the banking rules were not semantically comparable to their English counterparts at sentence level. Nor were they semantically comparable to their English counterparts at the level of paragraph.

Translations of banking rules and regulations is just one of many banking documents that are left unattended thus far; there are many other banking texts that have been 
translated and used in our daily banking exchanges, but few studies have been conducted to investigate the translation quality of such texts. Lack of translation precision in such documents could have grave consequences for the banking system and similar financial sectors. The issue gets more serious when it is born in mind that nearly all human beings all over the world deal somehow with the bank and banking issues. If so, then high quality translation would be in favor of all citizens globally, while improper translation could harm anybody dealing with the banking system.

The banking sector can help the economy of the coutry a lot by adopting a suitable, internationally well recognized language of exchange. Otherwise, a chaotic condition in financial sector, due to misunderstanding of banking documents, could happen, affecting different sections of the society. So seems safe to conclude that performance of a healthy banking industry is, to some extent, at the stake of precision in translation of internationally used banking documents, of which banking "rules and regulations" is just one instance.

\section{References}

[1] Aiken, M., \& Balan, Sh. (2011). An analysis of Google Translate accuracy. Trans/ation Journal, 16 (2): 1-3.

[2] Alwazna, Rafat, Y. (2013). Testing the precision of legal translation: The case of translating Islamic legal terms into English. International Journal for the Semiotics of Law -Revue internationale de Sémiotique juridique, 26(4), 897-907

[3] Byrne, J. (2006). Technical trans/ation usability strategies for translation technical documenta tion: Springer.

[4] Cao, D. (2007). Translating law, Multilingual matters. Multilingual Matters. Topics in Translation. pp. xii, 189.

[5] Chirila, E. (2016) Contemporary and Historical Resources for the Indigenous Languages of Australia. Language Documentation and Conservation, 10: 1-44.

[6] Doherty, S. (2016). The Impact of Translation Technologies on the Process and Product of Trans lation. International Journal of Communication 10: 947-969. Available at http://ijoc.org.

[7] Gawron-Zaborska, M. (2000): Le fantôme de la traduction littérale dans la traduction juridique, in ASTTI/ETI (2000), pp. 349-356.

[8] Goyal, R. (2013). Define what is banking? Definition of Banking. Basics of Banking. Banking for dummies. Retrieved from https://goo.gl/KH2ysN 
[9] Harvey, M. (2002). What's so special about Legal Translation? Journal des. TraducteurMeta: Translators' Journal, 47(2), 177-185.

[10] House, J. (1997). Translation quality assessment: A model revisited (Vol. 410): Gunter Narr Ver lag.

[11] Kasirer, N. (2000). "François Gény"s libre recherché scientifique as a Guide for Legal Translation". ASTTI/ETI, pp. 57-85.

[12] Lefevere, A. (2004). Trans/ation/History/Culture: A sourcebook. Shanghai: Shanghai Foreign Language Education Press, p. 176.

[13] Morris, M. (Ed.) (1995). Trans/ation and the Law, American Translators Association Scho larly Monograph Series, Vol. VIII; Philadelphia, John Benjamins Publishing Company.

[14] Nord, C. (2006). Loyalty and fidelity in specialized trans/ation. Confluências: Revista de Tradução Cientifica e Técnica, Heidelberg, Germany 4, 29-41.

[15] Robinson, Bryan. J.,Lopez Rodriguez, Clara, Tercedor Sanchez, and Maria, I. (2006). Self- assessment intranslator training. Perspectives, 14(2), 115-138.

[16] Sarcevic, S. (1997). New Approach to legal translation. Kluwer Law International.

[17] Zhao, Y. (2000). Legal translation in the legislative genre. Journal of Translation Studies, 4, 19-44.

[18] Zralka. E. (2007). Strategies in the trans/ation of legal texts-implication for translation pedagogy. 2016, the Unesco Chair fir Translation Studies and International Communication, Faculty of Philology, Jagiellonian University, Cracow 